\title{
CARACTERÍSTICAS CULTURAIS E PATOLÓGICAS DE Bipolaris maydis EM DIFERENTES MEIOS DE CULTURA
}

\author{
JULIANA SALTIRES SANTOS ${ }^{1}$, ANTONIO TEIXEIRA DO AMARAL JÚNIOR ${ }^{1}$, \\ MARCELO VIVAS ${ }^{1}$, JANIELI MAGANHA SILVA VIVAS ${ }^{1}$, \\ RAILAN NASCIMENTO FERREIRA KUROSAWA ${ }^{1}$ e SILVALDO FELIPE DA SILVEIRA ${ }^{1}$
}

\begin{abstract}
${ }^{1}$ Univesidade Estadual do Norte Fluminense Darcy Ribeiro, julianasaltiresdossantos@yahoo.com.br, amaraljr@pq.cnpq.br,mrclvivas@hotmail.com,janielims19@yahoo.com.br, railanferreira@hotmail.com,silvaldo@uenf.br
\end{abstract}

Revista Brasileira de Milho e Sorgo, v.15, n.3, p. 461-469, 2016

\begin{abstract}
RESUMO A mancha de Bipolaris, causada por Bipolaris maydis, é uma das principais doenças foliares de Zea mays, apresentando um considerável potencial de dano, notadamente, na cultura do milho-pipoca, embora trabalhos sobre este patossistema ainda sejam escassos. Neste trabalho, avaliaram-se as influências de diferentes meios de cultura sobre o crescimento micelial, esporulação e a infectividade de inóculo conidial de B. maydis em folhas da cultivar suscetível Beija-flor, de milho-pipoca. Para tal, instalaram-se experimentos em laboratório e em casa de vegetação em blocos casualizados com quatro repetições. Em laboratório, avaliaram-se o crescimento micelial e a esporulação de $B$. maydis em diferentes meios de culturas (Batata Dextrose Ágar, Feijão Ágar, Água de Coco Ágar, Arroz Polido Ágar, Folha de Milho Ágar e Lactose Caseína Ágar). Em casa de vegetação, avaliaram-se o número de lesões por folha e a incidência de doença na planta suscetível inoculada com uma suspensão de $10^{4}$ conídios $/ \mathrm{mL}$. O meio de Arroz Polido Ágar foi o que mais promoveu o crescimento micelial do fungo, porém não favoreceu a esporulação. Para esporulação, destacaram-se os meios de cultura Batata Dextrose Ágar e Feijão Ágar. Maior número de folhas com sintoma da doença e maior número de lesões por folha foram obtidos com o inóculo produzido no meio Feijão Ágar.
\end{abstract}

Palavras-Chave: Zea mays L., Crescimento micelial, Mancha de Bipolaris, Esporulação, Milho-pipoca.

\section{CULTURAL AND PATHOLOGICAL FEATURES OF Bipolaris maydis IN DIFFERENT CULTURE MEDIA}

\begin{abstract}
The Southern corn leaf blight, caused by Bipolaris maydis, is a major foliar disease of corn, presenting considerable potential of damage, especially in Zea mays, although studies with this pathosystem are still scarce. In this paper, the effect of different culture media was evaluated on mycelial sporulation and infectivity of conidial inoculum of B. maydis on leaves of the susceptible cultivar Beija-Flor, of corn-popcorn. Experiments in laboratory and greenhouse were installed in a randomized blocks design with four replications. The mycelial growth and sporulation of $B$. maydis on different culture media (Potato Dextrose Agar, Bean Agar, Coconut Water Agar, Rice Polished Agar, Corn Leaf Agar Lactose Casein Agar) were evaluated in the laboratory. In the greenhouse it was evaluated the number of lesions per leaf and the incidence of disease in susceptible plants inoculated with a suspension of $10^{4} \mathrm{conidia} / \mathrm{ml}$. The culture medium Polished Rice Agar promoted the highest mycelial growth, but did not promote sporulation. Sporulation was higher on culture media Potato dextrose Agar and Agar Bean. A greater number of leaves with symptoms of the disease and a higher number of lesions per leaf were obtained with the inoculum produced in the culture medium Bean Agar.
\end{abstract} Keywords: Zea mays L, Mycelial growth, Southern corn leaf bligh, Sporulation, Popcorn. 
O milho (Zea mays L.) destaca-se como uma das principais espécies cultivadas no mundo. Dentre os "milhos especiais", o pipoca tem exercido influência positiva em setores da economia nacional, por ser uma cultura de elevada rentabilidade, favorecendo, inclusive, a impactação da economia informal (Freitas Júnior et al., 2009). Todavia, pesquisas com resistência a doenças em milho-pipoca têm sido escassas (Ribeiro et al., 2016; Vieira et al., 2016), desfavorecendo a potencialização do agronegócio vinculado à cultura.

Dentre as doenças que atacam o milho no Brasil, as helmintosporioses são as mais importantes. Estas doenças são causadas por um complexo de fungos, dos quais se destacam Exserohilum turcicum (Pass.) K.J. Leonard \& Suggs [fase sexuada Setosphaeria turcica (Luttr.) K. J. \& Leonard Suggs] e Bipolaris maydis (Nisik. \& Miyake) Shoemaker [fase sexuada Cochliobolus heterostrophus (Drechsler) Drechsler]. O fungo E. turcicum é de ocorrência mundial (Carson \& Van Dyre, 1994; Ogliari et al., 2005; Harlapur et al., 2008) e destaca-se por causar mais de $40 \%$ de danos em condições ambientais favoráveis, principalmente em cultivares suscetíveis (Ferguson \& Carson, 2007; Wang et al., 2010). Os sintomas da doença são lesões foliares necróticas, de coloração palha, ou escuras com bordas bem definidas, largas, alongadas e grandes ( 5 a $8 \mathrm{~cm}$ de comprimento, em média), e distribuição irregular na superfície da folha (Camargo et al., 2005).

Por outro lado, na mancha de Bipolaris, as lesões foliares possuem uma coloração palha, de forma retangular, limitada por nervuras, de comprimento médio de 2,5 x 0,5 cm de largura (Camargo et al., 2005). Segundo Reis et al. (2004), a mancha de Bipolaris ocorre no milho com diferentes intensidades em função do grau de resistência, do sistema de manejo da lavoura e das condições de clima durante o culti- vo. Porém, como o milho-pipoca é menos resistente a esta doença, ela deve ser considerada de maior importância para esse tipo de milho (Oliveira et al., 2004).

Visando a minimizar o dano causado por doenças, várias medidas de controle são adotadas, dentre as quais destaca-se o plantio de variedades resistentes, que vem sendo uma das alternativas mais eficazes no controle, uma vez que o seu uso não gera custos adicionais ao produtor, não causa impacto negativo ao ambiente, sendo perfeitamente compatível com outras alternativas de manejo. Entretanto, na cultura do milho-pipoca, o uso de resistência genética, notadamente para B. maydis, ainda é escasso (Arnhold, 2008), carecendo de estudos de base para se iniciar um programa de melhoramento. Para que ocorram avanços no conhecimento sobre a resistência genética à mancha de Bipolaris, há necessidade de produção de inóculo e padronização das inoculações, o que é dificultado pela falta de informações sobre o crescimento e a esporulação do fungo em meio de cultura, etapa importante para a produção de inóculo.

Segundo Cruz et al. (2009), conseguir isolados esporulantes, ou mesmo padronizar condições ideais para a esporulação de fungos fitopatogênicos, constitui uma das principais dificuldades enfrentadas por grupos de pesquisa que visam à identificação de cultivares resistentes. Neste contexto, este trabalho visou a avaliar a influência de diferentes meios de cultura sobre o crescimento micelial, a esporulação infectividade do inóculo conidial de B. maydis.

\section{Material e Métodos}

\section{Obtenção do isolado}

Folhas de milho-pipoca com sintomas típicos de mancha de Bipolaris foram coletadas na Escola Técnica Estadual Agrícola Antônio Sarlo e conduzi- 
das ao Laboratório de Entomologia e Fitopatologia da Universidade Estadual do Norte Fluminense Darcy Ribeiro (UENF), em Campos dos Goytacazes, RJ, onde se procederam, a partir de um isolado, à identificação e ao posterior isolamento monospórico do fungo. Para a obtenção da cultura pura, foram realizados o isolamento em meio de cultura BDA e a incubação à temperatura de $25^{\circ} \mathrm{C}$ e com fotoperíodo de $12 \mathrm{~h}$.

Logo após, foi realizado o isolamento monospórico com o intuito de se purificar o isolado. As culturas monospóricas obtidas de um único isolado foram armazenadas em tubos de ensaio com meio de BDA em refrigerador $\left(10^{\circ} \mathrm{C}\right)$.

\section{Experimento de laboratório}

O experimento foi conduzido em blocos casualizados com quatro repetições, sendo que cada unidade experimental foi composta por uma placa contendo um determinado meio e um disco do fungo de $1 \mathrm{~cm}$ de diâmetro de cultura. Os meios de cultura testados foram: Batata Dextrose Ágar (BDA) (extrato de 200 $\mathrm{g}$ de batata, $20 \mathrm{~g}$ de dextrose, $20 \mathrm{~g}$ de ágar e $1.000 \mathrm{~mL}$ de água destilada), Lactose Caseína Hidrolisada Ágar (LCA) (37,5 g de lactose, $3 \mathrm{~g}$ de caseína hidrolisada, $1 \mathrm{~g}$ de $\mathrm{KH}_{2} \mathrm{PO}_{4}, 0,5 \mathrm{~g}$ de $\mathrm{MgSO}_{4}, 17 \mathrm{~g}$ de ágar e 1.000 $\mathrm{mL}$ de água), Folha de Milho Ágar (FMA) (30 g de sacarose, $20 \mathrm{~g}$ de ágar, $125 \mathrm{~mL}$ de água com folha de milho e $875 \mathrm{~mL}$ de água destilada), Água de Coco Ágar (ACA) (20 g de dextrose, $20 \mathrm{~g}$ de ágar e 1.000 $\mathrm{mL}$ de água de coco), Arroz Polido Ágar (APA) (20 g de ágar, $20 \mathrm{~g}$ de arroz e $1.000 \mathrm{~mL}$ de água destilada), Meio de Bean Ágar (MBA) (20 g de feijão triturado, $15 \mathrm{~g}$ de ágar e $1.000 \mathrm{~mL}$ de água destilada). Depois de instalado o experimento, as placas foram incubadas em BOD na temperatura de $25^{\circ} \mathrm{C}$, onde permaneceram até a avaliação. $\mathrm{O}$ experimento foi repetido nas mesmas condições anteriores.
Após 10 dias de cultivo, foi realizada a caracterização da colônia do fungo nos diferentes meios. A caracterização constituiu das avaliações das colorações do verso e do reverso da colônia, do aspecto da cultura (se aéreo ou superficial), da presença ou da ausência de halo e da borda regular ou irregular. Também se avaliaram o crescimento micelial e a esporulação.

A avaliação do crescimento micelial consistiu da medição do diâmetro da colônia ( $\mathrm{mm}$ ) em dois sentidos ortogonais, com auxílio de régua milimétrica. Para verificação da capacidade de esporulação, foi obtida uma suspensão de esporos, adicionandose $10 \mathrm{~mL}$ de água destilada esterilizada em cada placa. Uma alíquota de $10 \mu \mathrm{L}$ foi retirada para contagem dos esporos em câmara de Neubauer. Os dados foram submetidos à análise de variância e, quando constatado efeito significativo, efetuou-se o teste de média Scott-Knott utilizando o programa Genes (Cruz, 2013).

\section{Experimento em casa de vegetação}

Instalou-se experimento visando avaliar a infectividade do inóculo conidial de um isolado, produzido em diferentes meios de cultura. Foi utilizada a linhagem suscetível Beija-flor. O experimento foi conduzido em condições de telado, seguindo o delineamento experimental de blocos casualizados com três repetições, em que a unidade experimental constituiu de um vaso com uma planta. Este experimento foi repetido uma vez.

A inoculação das plantas foi realizada quando estas apresentaram de quatro a seis folhas totalmente expandidas, em torno da quarta semana após a emergência. As plantas foram inoculadas com $10 \mathrm{~mL}$ de uma suspensão de $10^{4}$ conídios/mL utilizando-se um atomizador manual. Essas plantas foram mantidas por mais 
24 h em câmara úmida. Após 24 h, as plantas foram expostas às condições normais do telado. As testemunhas constituíram de plantas não inoculadas e de plantas pulverizadas apenas com água destilada-esterilizada.

As avaliações foram realizadas no sétimo dia após a inoculação, observando-se individualmente os sintomas da doença, caracterizando-se o número, o formato e o tamanho da lesão, além da incidência de folhas com sintomas, que era constituída pelo número de folhas lesionadas. Os dados foram submetidos às análises de variâncias conjunta e individual e, quando constatado efeito significativo, efetuou-se o teste de média Scott-Knott utilizando o programa Genes (Cruz, 2013).

\section{Resultados e Discussão}

Pela avaliação das colorações da frente e do verso da colônia, pôde-se inferir que o meio em que o fungo foi cultivado interferiu no aspecto da colônia (Tabela 1). Observou-se coerência entre os caracteres avaliados no primeiro e no segundo experimentos para os meios BDA e MBA. Nestes meios, as colônias apresentaram a mesma coloração na frente e no verso das placas, com micélio aéreo, sem halos e com bordas irregulares (Tabela 1). Para o meio ACA, a colônia do fungo apresentou a mesma coloração nos dois experimentos (cinza claro - frente, marrom claro - verso), borda irregular e ausência de halo; no entanto, a colônia expressou diferença no seu aspecto, apresentando micélio superficial (primeiro ensaio) e aéreo (segundo ensaio). Para os demais meios, observaram-se variações tanto para a coloração, quanto para os demais caracteres avaliados entre os dois ensaios (Tabela 1). Dias Neto et al. (2008) observaram grande variação entre as características culturais das colônias fúngicas de Pyricularia grisea Sacc. quando avaliando diferentes meios de cultura. Fato semelhan- te foi observado por Mafacioli et al. (2006) para a espécie Colletotrichum. gloeosporioides (Penz.) Penz. \& Sacc. em isolados de cacaueiro, de mangueira, de cajueiro, de morangueiro e de pupunheira.

Nas avaliações de crescimento micelial e de esporulação, não se observou efeito significativo da interação entre meio versus experimento. Por este motivo, os resultados são apresentados com base na média dos dois experimentos. Para as duas variáveis em estudo, ou seja, crescimento micelial e esporulação, houve diferença significativa dos meios testados, sendo que APA, LCA e FMA foram os que mais favoreceram o crescimento micelial (Tabela 2). Por outro lado, os meios BDA e MBA foram os que proporcionaram as maiores médias de esporulação (Tabela 2). Foi observado também que o meio APA proporcionou maior velocidade de crescimento micelial, diferindo estatisticamente dos demais meios. Resultado semelhante foi observado por Pulz e Massola Júnior (2009) ao avaliarem isolados de Alternaria dauci (J.G. Kuhn) J.W. Groves \& Skolko e Alternaria solani Sorauer. Por conseguinte, conclui-se que os meios APA, LCA e FMA, embora tenham proporcionado um maior crescimento micelial, não foram eficientes para a produção de conídios, o que os descredencia para utilização em testes de inoculação, uma vez que a produção do inóculo será dificultada pela falta de conídios. Sabe-se que a composição do meio de cultura, a temperatura e a luminosidade determinam a quantidade e a qualidade do crescimento micelial, bem como a esporulação dos fitopatógenos (Dhingra \& Sinclair, 1995). Nozaki et al. (2004) afirmam que nem sempre as condições que favorecem o crescimento são as mesmas para esporulação, pois a luz exerce efeito direto sobre o fungo, induzindo ou inibindo a formação de estruturas reprodutivas. Segundo esses autores, alguns meios de cultura são mais favoráveis 
Tabela 1. Caracterização morfológica do isolado de Bipolaris maydis em diferentes meios de cultura: Batata Dextrose Ágar (BDA), Feijão Ágar (MBA), Água de Coco Ágar (ACA), Lactose Caseína Ágar (LCA), Folha de Milho Ágar (FMA) e Arroz Polido Ágar (APA).

\begin{tabular}{|c|c|c|c|c|c|}
\hline \multirow{3}{*}{ Meio } & \multicolumn{5}{|c|}{ Primeiro Ensaio } \\
\hline & \multicolumn{2}{|c|}{ Coloração } & \multirow{2}{*}{$\mathbf{A C}$} & \multirow{2}{*}{ Halo } & \multirow{2}{*}{ Borda } \\
\hline & Frente & Verso & & & \\
\hline $\mathrm{BDA}$ & Preta & Preta & Aéreo & Ausente & Irregular \\
\hline MBA & Cinza Escura & Preta & Aéreo & Ausente & Irregular \\
\hline $\mathrm{ACA}$ & Cinza Clara & Marrom Clara & Superficial & Ausente & Irregular \\
\hline LCA & Cinza Clara & Cinza Escura & Aéreo & Ausente & Irregular \\
\hline FMA & Cinza Escura & Cinza Escura & Aéreo & Presente & Irregular \\
\hline APA & Cinza Escura & Preta & Superficial & Presente & Irregular \\
\hline \multirow{3}{*}{ Meio } & \multicolumn{5}{|c|}{ Segundo Ensaio } \\
\hline & \multicolumn{2}{|c|}{ Coloração } & \multirow{2}{*}{$\mathbf{A C}$} & \multirow{2}{*}{ Halo } & \multirow{2}{*}{ Borda } \\
\hline & Frente & Verso & & & \\
\hline $\mathrm{BDA}$ & Preta & Preta & Aéreo & Ausente & Irregular \\
\hline MBA & Cinza Escura & Preta & Aéreo & Ausente & Irregular \\
\hline ACA & Cinza Clara & Marrom Clara & Aéreo & Ausente & Irregular \\
\hline LCA & Cinza Clara & Cinza Clara & Aéreo & Ausente & Irregular \\
\hline FMA & Verde Musgo & Verde Musgo & Superficial & Ausente & Irregular \\
\hline APA & Cinza Clara & Verde Musgo & Superficial & Presente & Irregular \\
\hline
\end{tabular}

Tabela 2: Média do crescimento micelial ( $\mathrm{cm})$ e esporulação $\left(10^{4}\right.$ conídios por $\left.\mathrm{mL}\right)$ do isolado de Bipolaris maydis em diferentes meios de cultura: Batata Dextrose Ágar (BDA), Feijão Ágar (MBA), Água de Coco Ágar (ACA), Lactose Caseína Ágar (LCA), Folha de Milho Ágar (FMA) e Arroz Polido Ágar (APA).

\begin{tabular}{ccc}
\hline Meio de cultura & Crescimento Micelial (cm) & $\begin{array}{c}\text { Esporulação } \\
\text { conídios por } \mathbf{~ m L})\end{array}$ \\
\hline ACA & $2,88 \mathrm{C}$ & $0,25 \mathrm{~B}$ \\
APA & $6,28 \mathrm{~A}$ & $3,63 \mathrm{~B}$ \\
BDA & $2,32 \mathrm{C}$ & $8,25 \mathrm{~A}$ \\
FMA & $4,48 \mathrm{~B}$ & $3,75 \mathrm{~B}$ \\
LCA & $4,80 \mathrm{~B}$ & $3,13 \mathrm{~B}$ \\
MBA & $3,47 \mathrm{C}$ & $7,13 \mathrm{~A}$ \\
\hline
\end{tabular}

Para uma mesma característica, médias seguidas pelas mesmas letras constituem grupo estatisticamente homogêneo.

para a esporulação de fungos que outros, por apresentarem carboidratos complexos que são menos adequados para a produção de hifas vegetativas; porém, mais adequados à produção de esporos. Concordando com o afirmado por Nozaki et al. (2004), neste trabalho observou-se que os meios que favoreceram o crescimento micelial não foram os mesmos que favoreceram a esporulação.

Segundo Cruz et al. (2009), um dos principais desafios quando se trabalha com resistência genética de plantas está em estabelecer as condições ideais de cultivo e se pré-selecionar isolados esporulantes. $\mathrm{O}$ 
meio MBA foi o mais adequado à produção de conídios. Ademais, este meio não utiliza glicose, conferindo uma vantagem adicional na comparação com o meio BDA. Sendo a virulência fortemente dependente das condições nutricionais, Shah et al. (2005) relatam que, em geral, os conídios que são produzidos em meios que apresentam maior produção não são os mais eficazes em causar virulência, tornando-se importante a realização de avaliações que evidenciem a capacidade dos conídios produzidos.

No trabalho conduzido em casa de vegetação, observou-se que todos os meios testados produziram
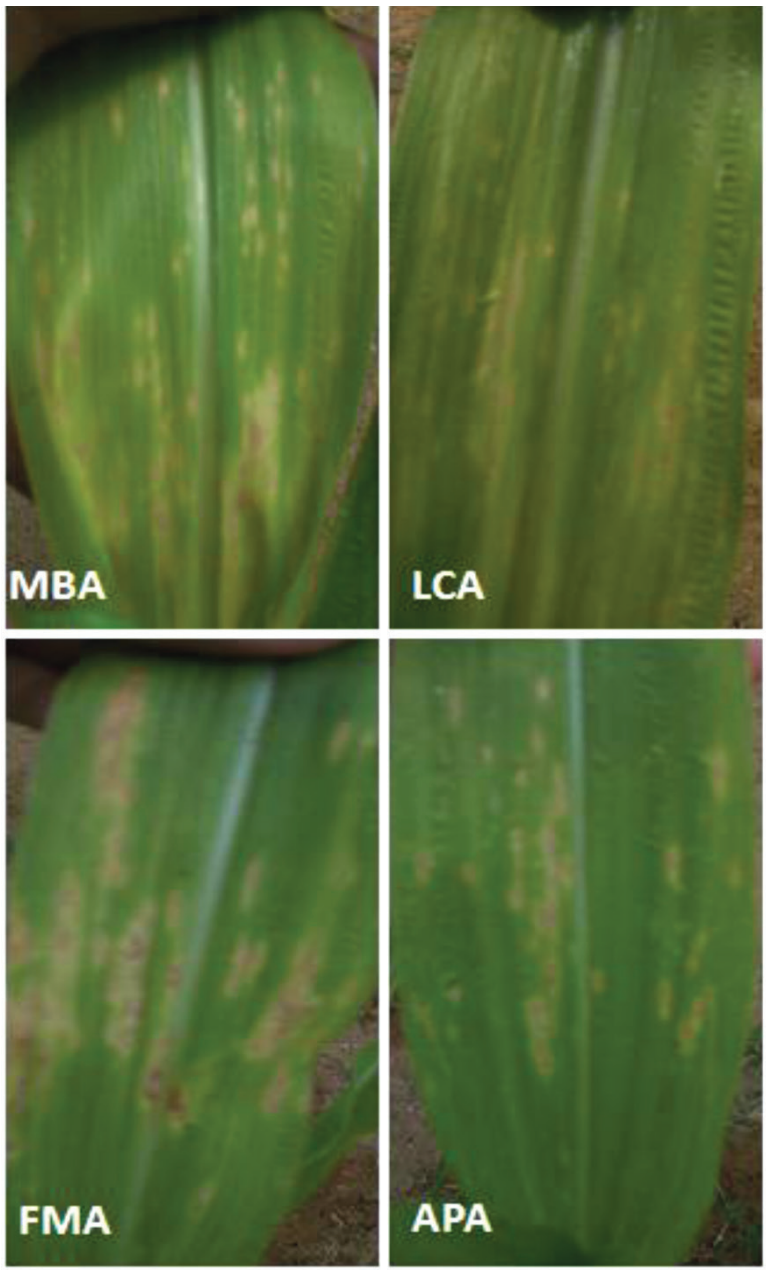

conídios infectivos capazes de causar sintomas (Figura 1). Observou-se também que, tanto para o número de lesões por folha quanto para incidência de folhas com sinais do patógeno, houve efeito significativo da interação meio de cultura versus experimento. Portanto, foram conduzidas análises separadas para os dois ensaios. As condições ambientais não foram discrepantes entre os dois experimentos, haja vista que o tempo entre a conclusão de um e o início do outro foi de aproximadamente um mês.

Para o número de lesões por folha, observou-se que os conídios crescidos em meio MBA, no primeiro
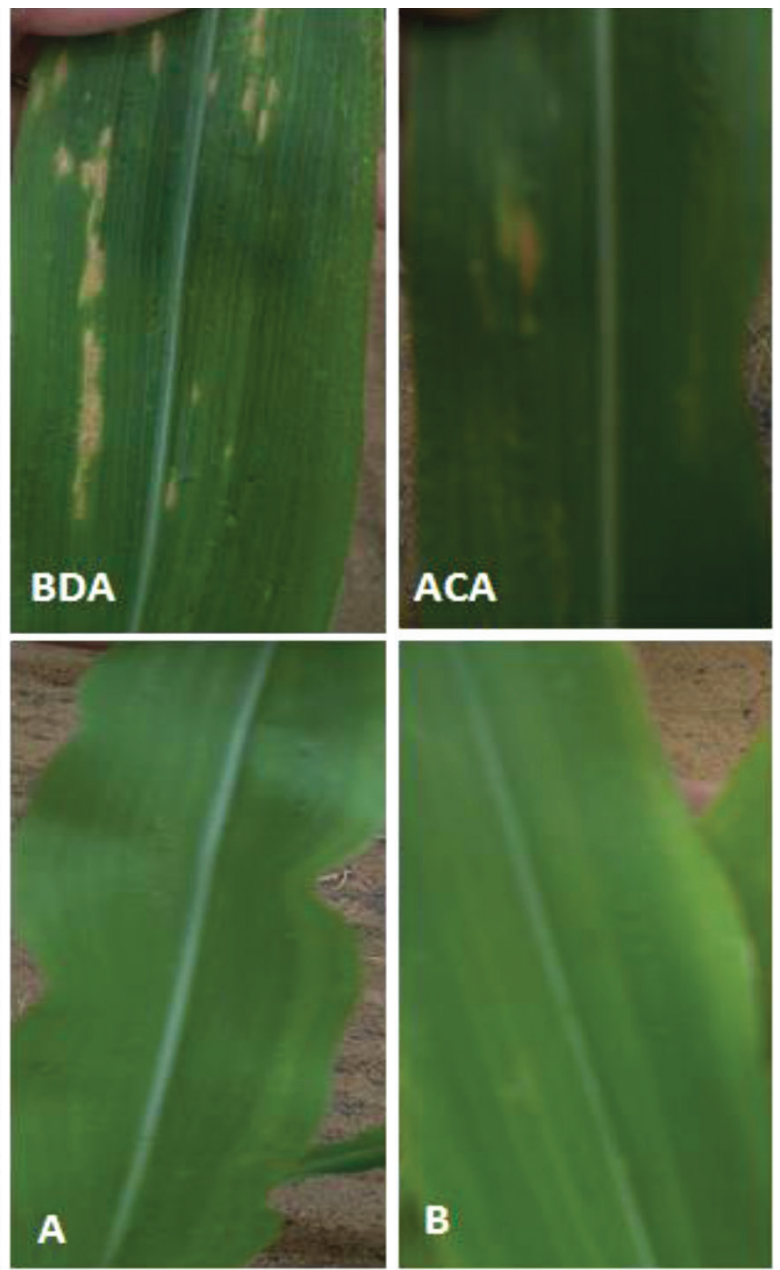

Figura 1. Sintomas de mancha de Bipolaris em folhas inoculadas com conídios produzidos em meio de MBA, LCA, BDA, ACA, FMA e APA e ausência de lesões nas folhas pulverizadas com água (A) e não inoculadas (B). 
ensaio, causaram a maior quantidade de lesões, em média 34 (Tabela 3). Além deste, observou-se também um grande número de lesões para os meios BDA, FMA e LCA, superiores aos obtidos nos meios ACA e APA; portanto, estes meios que proporcionaram o desenvolvimento de conídios mais infectivos podem, por conseguinte, ser considerados como adequados para o desenvolvimento deste fungo. Nos dois experimentos, não foram observados sintomas nas testemunhas (sem inoculação e pulverizando-se apenas água), ratificando, assim, que as lesões apresentadas na planta foram provenientes das inoculações dos conídios. As maiores médias de lesões foram observadas em plantas inoculadas com conídios produzidos nos meios MBA e BDA, ratificando sua superioridade (Tabela 3).

Considerando a incidência de folhas com lesões, observou-se no primeiro ensaio que o meio FMA apresentou a maior incidência de folhas com sintomas, em média 47\%; entretanto, este meio não diferiu significativamente dos meios MBA, LCA, APA e BDA e, embora tenham apresentado menores valores para incidência de folhas com lesões, não foram separados em grupos distintos. As folhas inoculadas com conídios crescidos em meio ACA não apresentaram sintomas da doença, o que ocasionou a separação desse meio dos demais; isto porque provavelmente os conídios produzidos foram menos infectivos e, consequentemente, menos virulentos, o que resultou em folhas assintomáticas. Porém, no segundo ensaio, as plantas inoculadas com conídios produzidos nos meios ACA, MBA e BDA apresentaram maior número de folhas com sintomas da doença, diferindo significativamente dos outros meios, bem como das testemunhas. Ressalta-se que os meios MBA e BDA já haviam se destacado para as demais características, confirmando a superioridade de ambos.

Tabela 3. Média da incidência de folhas com sintomas da doença e do número de lesões de Bipolaris maydis em plantas inoculados com conídios produzidos em diferentes meios de cultura Batata Dextrose Ágar (BDA), Feijão Ágar (MBA), Água de Coco Ágar (ACA), Lactose Caseína Ágar (LCA), Folha de Milho Ágar (FMA) e Arroz Polido Ágar (APA). Inoculadas com Água (A) e não inoculadas (B).

\begin{tabular}{|c|c|c|c|c|c|c|c|c|c|c|c|c|}
\hline \multirow{3}{*}{$\begin{array}{l}\text { Meio } \\
\text { ACA }\end{array}$} & \multicolumn{6}{|c|}{ Número de Lesões por folha } & \multicolumn{6}{|c|}{ Incidência de folhas que apresentaram sintomas } \\
\hline & \multicolumn{3}{|c|}{ Primeiro Ensaio } & \multicolumn{3}{|c|}{ Segundo Ensaio } & \multicolumn{3}{|c|}{ Primeiro Ensaio } & \multicolumn{3}{|c|}{ Segundo Ensaio } \\
\hline & 0.0 & A & $\mathrm{c}$ & 2.8 & $\mathrm{~A}$ & $\mathrm{a}$ & 0.0 & $\mathrm{~B}$ & $\mathrm{~b}$ & 17.6 & A & $\mathrm{a}$ \\
\hline APA & 9.0 & A & $\mathrm{c}$ & 3.0 & A & $\mathrm{a}$ & 38.0 & A & $\mathrm{a}$ & 7.2 & $\mathrm{~B}$ & $\mathrm{~b}$ \\
\hline BDA & 13.6 & A & $\mathrm{b}$ & 7.6 & A & $\mathrm{a}$ & 26.7 & A & $\mathrm{a}$ & 13.0 & A & $\mathrm{a}$ \\
\hline FMA & 21.6 & A & b & 0.0 & B & $\mathrm{a}$ & 47.5 & A & $\mathrm{a}$ & 0.0 & B & $\mathrm{b}$ \\
\hline LCA & 18.3 & A & b & 2.8 & B & $\mathrm{a}$ & 41.7 & A & $\mathrm{a}$ & 5.0 & B & $\mathrm{b}$ \\
\hline MBA & 34.5 & A & $\mathrm{a}$ & 13.5 & B & $\mathrm{a}$ & 44.7 & A & $\mathrm{a}$ & 19.7 & B & $\mathrm{a}$ \\
\hline A & 0.0 & A & $\mathrm{c}$ & 0.0 & A & $\mathrm{a}$ & 0.0 & A & $\mathrm{b}$ & 0.0 & A & $\mathrm{b}$ \\
\hline B & 0.0 & A & $\mathrm{c}$ & 0.0 & A & $\mathrm{a}$ & 0.0 & A & $\mathrm{b}$ & 0.0 & A & $\mathrm{b}$ \\
\hline
\end{tabular}

Para uma mesma característica, médias seguidas pelas mesmas letras maiúsculas na horizontal constituem grupo estatisticamente homogêneo e médias seguidas pelas mesmas letras minúsculas; e, na vertical, constituem grupo estatisticamente homogêneo. 


\section{Conclusão}

Os meios MBA e BDA são indicados para produção de inóculo de $B$. maydis, pois favoreceram a maior produção de conídios. Plantas inoculadas com conídios produzidos nestes meios apresentaram maiores números de lesões e incidência de folhas sintomáticas.

\section{Referências}

ARNHOLD, E. Seleção para resistência a doenças foliares em famílias $\mathrm{S}_{1}$ de milho-pipoca. Revista Ceres, Viçosa, MG, v. 55, p. 89-93, 2008.

BRUGNERA, A.; VON PINHO, R. G.; PACHECO, C. A. P.; ALVAREZ, C. G. D. Resposta de cultivares de milho pipoca a doses de adubação de semeadura. Revista Ceres, Viçosa, MG, v. 50, p. 417-429, 2003.

CAMARGO, L. E. A.; PEREIRA, O. A. P.; CARVALHO, R. V. de. Doenças do milho. In: KIMATI, H.; AMORIM, L.; BERGAMIN FILHO, A.; CAMARGO, L. E. A.; REZENDE, J. A. M. (Ed.). Manual de fitopatologia: doenças das plantas cultivadas. 4. ed. São Paulo: Agronômica Ceres, 2005. p. 477-488.

CARSON, M. L.; VAN DYRE, C. G. Effect of light and temperature on expression of partial resistance of maize to Exserohilum lurcicum. Plant Disease, St. Paul, v. 78, p. 519-522, 1994. DOI: 10.1094/PD-78-0519.

CRUZ, C. D. GENES: a software package for analysis in experimental statistics and quantitative genetics. Acta Scientiarum Agronomy, Maringá, v. 35, n. 3, p. 271-276, 2013.DOI: 10.4025/actasciagron.v35i3.21251.

CRUZ, M. F. A.; PRESTES, A. M.; MACIEL, J. L. N. Esporulação de Pyricularia grisea em diferentes meios de cultura e regimes de luz. Ciência Rural, Santa Maria, v. 39, n. 5, p. 1562-1564, 2009. DOI: $10.1590 / \mathrm{S} 0103-84782009000500040$.
DHINGRA, O. D.; SINCLAIR, J. B. Basic plant pathology methods. 2nd. Boca Raton: CRCPress, 1995. 448 p.

DIAS NETO, J. J.; SANTOS, G. R.; SILVA, L. M. A.; RANGEL, P. H. N.; FERREIRA, M. E.; CUNHA, A. C. F.; CANJÃO, E. R.; CASTRO NETO, M. D. Identificação de raças fisiológicas de Pyricularia grisea em arroz no Estado do Tocantins. Tropical Plant Pathology, Brasília, DF, v. 33, p. 186, 2008. Suplemento.

FERGUSON, L. M.; CARSON, M. L. Temporal variation in Setosphaeria turcica between 1974 and 1994 and origin of races 1, 23, and 23N in the United States. Phytopathology, Saint Paul, v. 97, n. 11, p. 1501-1511, 2007.

DOI: 10.1094/PHYTO-97-11-1501.

FREITAS JÚNIOR, S. de P.; AMARAL JÚNIOR, A. T.; RANGEL, R. M.; VIANA, A. P. Genetic gains in popcorn by full-sib recurrent selection. Crop Breeding and Applied Biotechnology, Londrina, v. 9, p. 1-7, 2009.

HARLAPUR, S. I.; KULKARNI, M. S.; WALI, M. C.; SRIKANT, K.; YASHODA, H.; PATIL, B. C. Status of turcicum leaf blight of maize in Karnataka. Karnataka Journal of Agricultural Science, Cambridge, v. 21, n. 1, p. 55-60, 2008.

MAFACIOLI, R.; TESSMAN, D. J.; SANTOS,A.F.; VIDA, J. B. Caracterização morfo-fisiológica e patogenicidade de Colletotrichum gloeosporioides da pupunheira. Summa Phytopathologica, Botucatu, v. 32, n. 2, p. 113-117, 2006. DOI: $10.1590 / \mathrm{S} 0100-54052006000200003$.

NOZAKI, M. H.; CAMARGO, M. E.; BARRETO, M. Caracterização de Diaporthe citri em diferentes meios de cultura, condições de temperatura e luminosidade. Fitopatologia Brasileira, Brasília, DF, v. 29, n. 4, p. 429432, 2004. DOI: $10.1590 / \mathrm{S} 0100-41582004000400012$.

OGLIARI, J. B.; GUIMARÃES, M. A.; GERALDI, I. O.; CAMARGO, L. E. A. New resistance genes in the Zea mays-Exserohilum turcicum pathosystem. Genetics and Molecular Biology, Ribeirão Preto, v. 28, n. 3, p. 435-439, 2005.

DOI: $10.1590 / \mathrm{S} 1415-47572005000300017$. 
OLIVEIRA, E.; FERNANDES, F. T.; CASELA, C. R.; PINTO, N. F. J. A.; FERREIRA, A. S. Diagnose e controle de doenças na cultura do milho. In: GALVÃO, J. C. C.; MIRANDA, G. V. (Ed.). Tecnologias de produção do milho: economia, cultivares, biotecnologia, safrinha, adubação, quimigação, doenças, plantas daninhas e pragas. Viçosa, MG: UFV, 2004. p. 227-268.

PULZ, P.; MASSOLA JÚNIOR, N. S. Efeito de meios de cultura e fatores físicos no crescimento e esporulação de Alternaria dauci e A. solani. Summa Phytopathologica, Botucatu, v. 35, n. 2, p. 121-126, 2009.

DOI: $10.1590 / \mathrm{S} 0100-54052009000200007$.

REIS, E. M.; CASA, T.; BRESOLIN, A. R. Manual de diagnose e controle de doenças do milho. Passo Fundo: Aldeia Norte, 2004. 141 p.

RIBEIRO, R. M.; AMARAL JÚNIOR, A. T.; PENA, G. F.; VIVAS, M.; KUROSOWA, R. N.; GONÇALVES, L. S. A. Effect of recurrent selection on the variability of the UENF-14 popcorn population. Crop Breeeding and
Applied Biotechnology, Londrina, v. 16, p. 123-131, 2016. DOI: 10.1590/1984-70332016v16n2a19.

SHAH, F. A.; WANG, C. S.; BUTT, T. M. Nutrition influences growth and virulence of the insect-pathogenic fungus Metarhizium anisopliae. FEMS Microbiology Letters, Malden, v. 251, n. 2, p. 259-266, 2005.

DOI: 10.1016/j.femsle.2005.08.010.

VIEIRA, R. A.; SCAPIM, C. A.; TESSMANN, D. J.; FERREIRA, F. R. A.; VIVAS, M.; AMARAL JÚNIOR, A. T. A nonparametric approach to selection popcorn hybrids to resistance to foliar diseases. Científica, Jaboticabal, v. 44, p. 165-169, 2016.

DOI:10.15361/1984-5529.2016v44n2p165-169.

WANG, P.; SOUMA, K.; KOBAYASHI, Y.; IWABUCHI, K.; SATO, C.; MASUKO, T. Influences of Northern Leaf Blight on corn silage fermentation quality, nutritive value and feed intake by sheep. Animal Science Journal, Tokyo, v. 81, n. 4 , p. $487-493,2010$.

DOI: $10.1111 / \mathrm{j} .1740-0929.2010 .00757 . x$. 